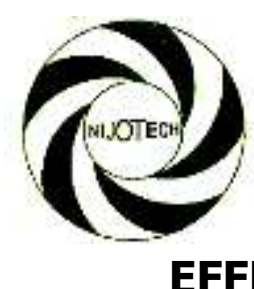

Nigerian Journal of Technology (NIJOTECH)

Vol. 38, No. 1, January 2019, pp. 48 - 51

Copyright@ Faculty of Engineering, University of Nigeria, Nsukka

Print ISSN: 0331-8443, Electronic ISSN: 2467-8821 http://dx.doi.org/10.4314/njt.v38i1.7 www.nijotech.com

\title{
EFFECT OF RICE-HUSK-ASH ADMIXTURE ON THE STRENGTH AND WORKABILITY OF CONCRETE
}

\author{
B. O. Adinna ${ }^{1,}{ }^{*}$, C. M. O. Nwaiwu ${ }^{2}$ and C. J. Igwagu ${ }^{3}$ \\ 1, 2, 3, Department of Civil Engineering NnAmdi AZikiwe University, AWKA, ANAMBra STATE, NIGERIA \\ E-mail addresses: ${ }^{1}$ adinnaboniface@yahoo.com, ${ }^{2}$ nknwaiwu@yahoo.co.uk, \\ 3 chukwuagoziejoshua4@gmail.com
}

\begin{abstract}
For over two decades, rice-husk-ash has been discovered to be a highly reactive pozzolana and has been used to substitute a portion of the cement content in concrete mix in order to reduce the cost of concrete manufacture and environmental hazards posed by rice-husk in rice producing areas. This research focuses on the possibility of using rice-husk-ash as strength enhancement admixture in concrete. Rice-husk-ash was added in small percentages of 2, 4, 7, 10 and 12\% to concrete mixtures. The workability was tested using slump test, while strength of the cubes after 28 days curing were obtained with a universal testing machine. The results showed that for concretes of medium workability the strength of the concrete containing RHA increased to $25 \%$ above the normal concrete of the same mix proportion at 7\%. Further addition of RHA above $7 \%$ and below 10\% reduced the workability very low but still good for mass concrete. Above 10\%, improvement in strength ceased and the concrete became very dry. Based on the result of the tests, addition of 7\% RHA by weight of cement will improve the strength of the concrete without appreciable change in the initial workability. In the case where the initial workability may be altered from medium to low workability, up to $10 \%$ RHA may be added. In other words RHA can be added to concrete mix up to $10 \%$ by weight of the cement content as long as the resulting change in the workability remains acceptable for the concreting work in question.
\end{abstract}

Keywords: Rice-husk-ash, admixture, Concrete strength, Workability

\section{INTRODUCTION}

Admixtures are materials used in concrete production which are added in small amount to the concrete during mixing in order to improve one of the concrete's property or the other. Admixtures are different from additives which are materials added to the cement at the factory during the grinding stage of the clinker [1]. In the past, the practice of using admixture was viewed as irrelevant, because of the erroneous perception that admixtures only improve one property of the concrete and reduce the other. Today the science of admixture has so advanced that virtually every property of the concrete can be improved. The benefit has been the great diversity in the production and use of concrete. Nowadays, one cannot think of sky scraper and lengthy bridge construction without thinking about high strength concrete, or to improve workability to reduce labour without plasticizers. Pumping of concrete is gradually becoming common and use of transit mixers and central batching plants has long been a common practice. All these are the benefits of admixtures, the study of which has become a substantial part of today's concrete technology.

Many different chemicals and minerals are used as admixtures, among these are pozzolanas. A pozzolana can be defined as silicious or silicious/ aluminious compounds which has no cementitious property, but in the presence of calcium hydroxide or lime, acquires cementitious property. Pozzolanas can occur naturally or are produced artificially. Natural pozzolanas are for example the volcanic ash and tuffs, which were mineral deposits near Mount Vesuvius in Pozzuali village in Italy, from where the

* Corresponding author, tel: +234-812-501-8455 
name 'pozzolana' was derived and later, applied to every substance having similar property on concrete. In 200AD, the Romans and the Greeks used volcanic ash in combination with lime in the production of a superior concrete of the contemporary time whose structures are still standing in fairly good condition today. The use of natural pozzolanas is now obsolete as they have been replaced by many artificial pozzolanas e.g. Rice-husk-ash, fly ash, silica fume, etc. [2].

The highly pozzolanic quality of rice- husk-ash is proven by the many published articles on this subject, many of which are centered on the substitution of a part of cement used in concrete with rice-husk-ash to obtain the same or nearly the same strength at 28-days curing period. The outcomes of these researches which generally prove that 10 percent substitution of cement with rice-husk-ash (by weight of cement content) produced the same strength at 28 days of curing with the normal concrete, served the purpose of reducing cost of concrete production and environmental hazards in rice producing areas [3-6]. There is need to investigate the effect of adding rice-rusk-ash in small amount to the concrete to improve some of the properties of the concrete, knowing that rice-huskash is a very reactive pozzolana. This study is therefore aimed at investigating the effect of ricehusk-ash on the strength and workability of concrete, when used as admixture.

Table 1: Oxide composition of Rice Husk Ash (RHA) burnt at $600-700^{\circ} \mathrm{C}$

\begin{tabular}{cc}
\hline Oxides & Percentage composition \\
\hline $\mathrm{SiO}_{2}$ & 88.32 \\
$\mathrm{AL}_{2} \mathrm{O}_{3}$ & 0.46 \\
$\mathrm{CaO}$ & 0.67 \\
$\mathrm{Fe}_{2} \mathrm{O}_{3}$ & 0.67 \\
$\mathrm{MgO}_{\mathrm{Na}}$ & 0.44 \\
$\mathrm{Na}_{2} \mathrm{O}$ & 0.21 \\
$\mathrm{~K}_{2} \mathrm{O}$ & 2.91 \\
$\mathrm{SO}$ & - \\
$\mathrm{LOI}$ & 5.81 \\
\hline
\end{tabular}

It is expected that the outcome of the study will serve as a guide for effective use of rice-husk-ash as strength enhancing admixture in concrete production, thereby making rice-husk-ash useful all over the globe for concrete production (and not restricted to rice producing area) and also further reduce environmental hazard associated with rice husk handling. Table1 shows the oxide composition of rice-husk-ash as a proof of its high pozzolanic activity.

\section{METHODOLOGY}

\subsection{Materials}

The materials used were river sand, crushed granite gravels, Portland cement and rice-husk-ash. The river sand was naturally clean, washed by a flowing river. It was well graded with a maximum size of $2 \mathrm{~mm}$. The granite gravel was also clean of dust and had a maximum size of $12 \mathrm{~mm}$. Rice-husk-ash was processed from husk obtained from a local rice mill. It was burnt in a murphy furnace at a controlled temperature of $600^{\circ} \mathrm{c}$. The resulting ash, grey in colour, was ground by rolling it on a very smooth surface to make it fine enough for use. It was then preserved in an air-tight container to prevent crystallization. The cement was a grade $42.5 \mathrm{~N} / \mathrm{mm}^{2}$, normal hardening Portland limestone cement, by Nigerian standard. The equipment used includes 150 x 150 x150-mm cube mould.

\subsection{Experimental Procedures}

The quantity of sand, gravel, cement, rice-husk-ash and water were carefully calculated and weighed out in such a quantity that can fill three cube moulds at a time, using a mix proportion of 1:2:4. Cement, ricehusk-ash and sand were thoroughly mixed using shovel on a nonabsorbent surface, before the gravel was added and mixed again, before water was added and the final mixing was done until the paste became uniformly plastic. The paste was fed in three layers into the slump cone placed on the glass plate. Each layer was uniformly tamped 25 times. The cone was raised and the slump measured. Using the same paste three concrete cubes were cast to B.S 1881 standard [7].

This process was applied to $0 \%, 2 \%, 4 \%, 7 \%, 10 \%$ and $12 \%$ rice-husk-ash addition to the concrete by weight of cement. The 18 concrete cubes were cured in a curing tank for 28 days, after which they were crushed with the aid of universal testing machine, and the average concrete cube strengths determined for each percentage addition of rice-husk-ash - the mix containing $0 \%$ rice-husk-ash was used as the control, while water-to-binder ratio of 0.53 was maintained for all specimens in the experiment. Table 2 shows the quantity of materials mixed for each specimen for three concrete cubes. 
Table 2: Relative quantities of materials used for the concrete production, at constant weight of cement (3.98kg), gravel $(15.93 \mathrm{~kg})$ and sand $(7.97 \mathrm{~kg})$

\begin{tabular}{cccc}
\hline $\begin{array}{c}\text { Experiment } \\
\text { designation }\end{array}$ & $\begin{array}{c}\text { Rice-Husk- Ash } \\
(\mathrm{g})\end{array}$ & $\begin{array}{c}\text { Water } \\
(\mathrm{kg})\end{array}$ & $\begin{array}{c}\text { Percentage addition of Rice-Husk-Ash by weight of } \\
\text { cement }(\%)\end{array}$ \\
\hline I (control) & 0 & 2.109 & 0 \\
2 & 79.6 & 2.153 & 2 \\
3 & 159.2 & 2.194 & 4 \\
4 & 278.6 & 2.257 & 7 \\
5 & 398.0 & 2.320 & 10 \\
6 & 477.6 & 2.363 & 12 \\
\hline
\end{tabular}

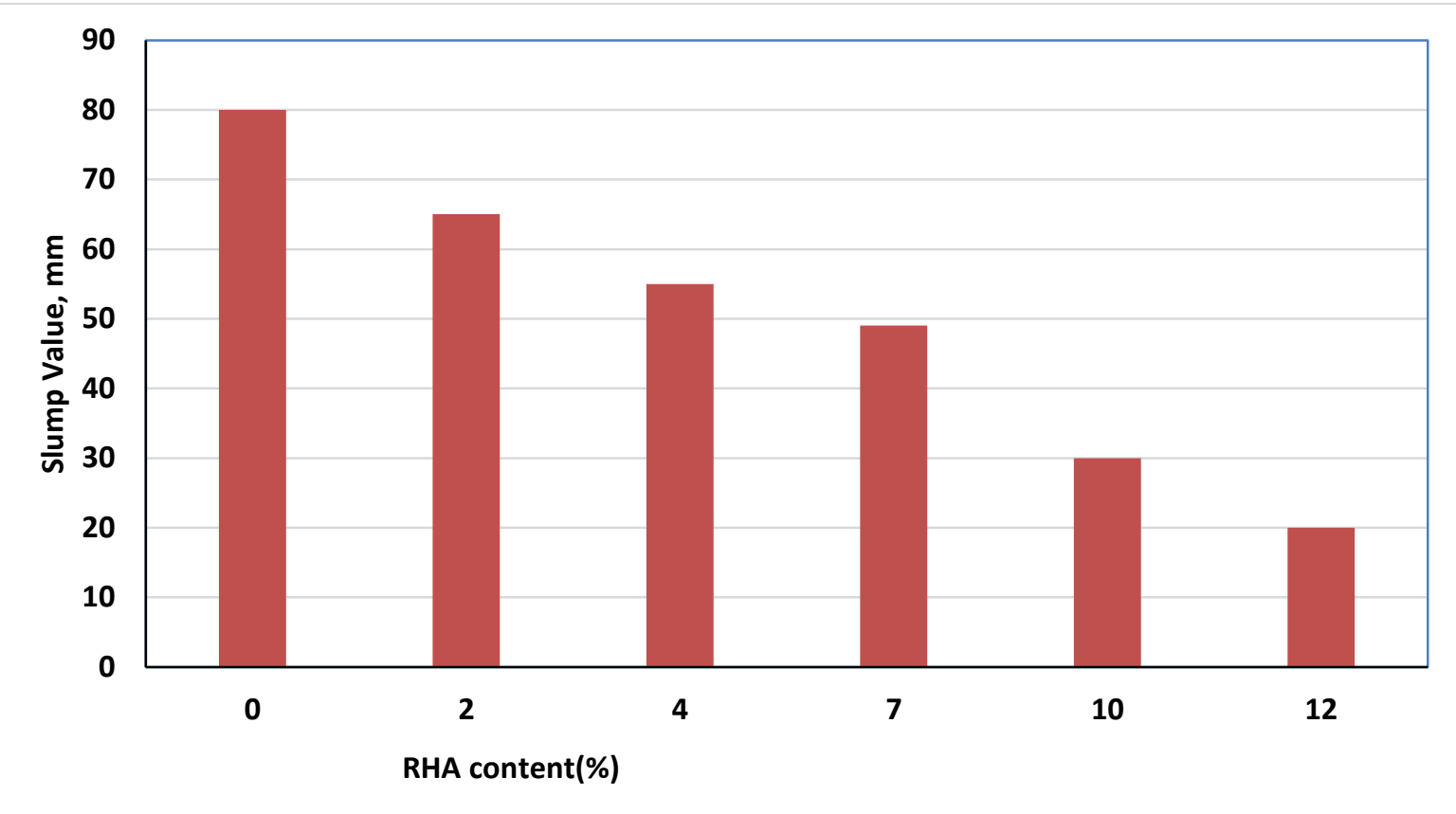

Fig. 1: Variation of Slump with RHA content (\%)

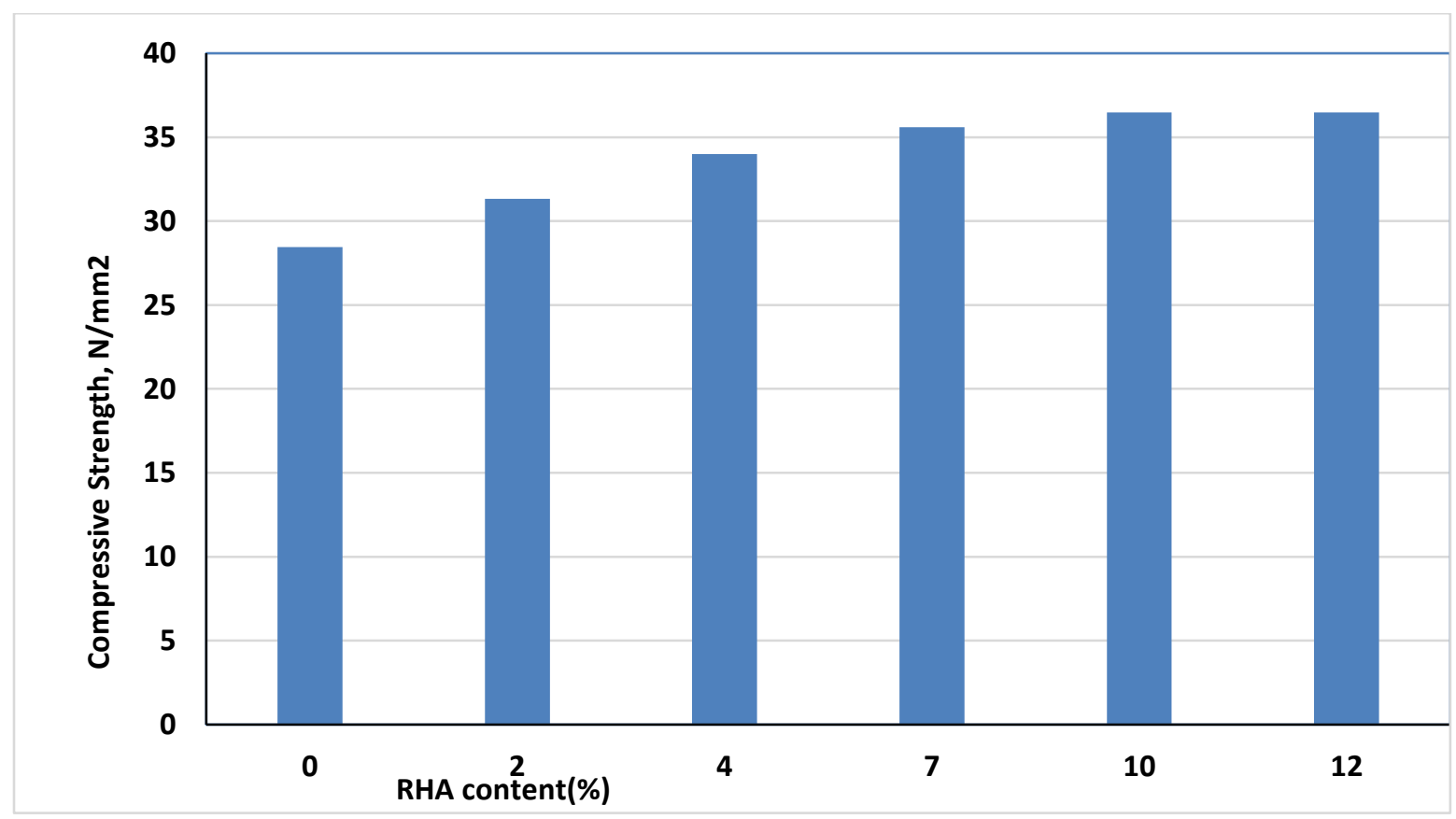

Fig. 2: Variation of Compressive Strength with RHA content (\%) 


\section{RESULT AND DISCUSSION}

The result of the slump and compressive strength test on fresh and hardened concretes with $0 \%, 2 \%$, $4 \%, 7 \% 10 \%$ and $12 \%$ of rice-husk-ash addition are given in the bar charts in Figs. (1) and (2)

From the results it is clear that the strength of concrete increases uniformly up to $4 \%$ addition of RHA. From $4 \%$, the rate of strength increase reduced with increase in percentage addition of RHA, and became constant from $10 \%$, see Fig. (2). This is in agreement with the findings of Allen [2]; Aboshio, Ogork and Balami [8].

Slump values also decreased with RHA content. There was a sharp reduction in slump from $10 \%$ RHA. The slump is a limiting factor to the continued addition of RHA, since it reduces with increase in RHA content. This means that concretes with higher water-to-cement ratio will need more RHA before the mix becomes unworkable. The initial slump or initial consistency of the concrete affects the quantity of RHA added. The initial slump of the concrete used for this experiment $(80 \mathrm{~mm})$ can be classified as medium workability. Workability can be classified as low when it gets below $50 \mathrm{~mm}$. Medium workability is good for lightly reinforced concrete sections without vibration or heavily reinforced section with vibration, while low workability is generally for mass concrete [9]. For concretes with initial slump different from the one used in the experiment, rice-husk-ash should be added until the range of workability suitable for the concreting work is reached, but not exceeding $10 \%$ by weight of the cement content.

\section{CONCLUSION}

We conclude by noting that for concretes of slump within $50-100 \mathrm{~mm}$ (medium workability) rice-husk-ash can be added up to $7 \%$ to achieve up to $20 \%$ increase in the compressive strength of the concrete. However, for other initial workabilities the quantity added should depend on the required workability up to a maximum of $10 \%$ by weight of cement.

\section{RECOMMENDATIONS}

Based on the results of the tests, addition of 7\% RHA to concrete is recommended for use in concrete of initial medium workability ( 50 to $100 \mathrm{~mm}$ slump) to achieve a strength gain of about $20 \%$. The quantity of RHA added should depend on the expected workability but never exceeding $10 \%$ by weight of the cement.

\section{REFERENCES}

[1] Shetty, M. S: "Concrete Technology" $2^{\text {nd }}$ ed, S. Chand and Company Ltd, Ram Nagar, New Delhi, 2009.

[2] Feber, J. H: "40 years of Ash Marketing in the USA, proceedings of the utilization of Ash Workshop", May 13-15, University of North Dakota, Grand Forks ND; Pp. 1-1-1-7, 1987.

[3] Allen, M. L: "The manufacture of cement Extender from Rice-Husks using a basketBurner", Current Science. Vol. 87, No 7, 2004.

[4] Oyetola, E. B. and Abdullahi M: "The use of Rice Husk Ash in low-cost sandcrete Block production", Leonardo Electronic Journal of Practice and Technology Issue 8, pp 58-70, 2006.

[5] Mauric, E. E;Godwin, A. A and Joseph, O.U: "Compressive strength of concrete with rice husk ash as a partial replacement of ordinary Portland cement", Scholary Journal of Engineering Research, vol. 1 (2), pp.33-36, 2012.

[6] Ghassan, A. H and Mahmud, H.B: "Study of properties of Rice Husk Ash and its uses as cement replacement material", Material Research Issue 13 Vol. 2, pp. 185-190, 2010

[7] B.S. 1881: Part 1: "Method of Testing concrete", British standard code of practice, London, 1970.

[8] Aboshio, A. Ogork;E. N and Balami, D. A: "Rice Husk ash as admixture in concrete", Journal of Engineering Technology, vol.4 (2) 2009.

[9] Jackson, N: "Civil Engineering Materials", English language book society and Macmillan, Honking, 1981. 